\title{
Living with and dying from cancer: a humanities special study module
}

Deborah Kirklin, Richard Meakin, Surinder Singh, Margaret Lloyd Royal Free and University College Medical School

\begin{abstract}
We describe a humanities-based, special studies module (SSM) exploring the impact of cancer on the lives of patients, families and professionals. Literature, film, art and drama provide third year medical undergraduates with vicarious experience of all of these perspectives in a format that has proved highly acceptable to students and tutors. The development, delivery, evaluation and evolution of this humanities-based course are described and we highlight some important elements of course organisation that emerged as being integral to its success.
\end{abstract}

(F Med Ethics: Medical Humanities 2000;26:51-54)

Keywords: Humanities; special study module; medical undergraduates; medical education; cancer

"The frisson you get from a fine line of poetry comes chiefly, I think, from the sheer pleasure that someone has recorded something you thought only you had felt before. More than that, it comes from the realisation that many others have shared and will share with you this moment that you had thought was unique and inexpressible. The loneliness of the individual life is dissolved briefly in the flicker of that same sensation, of coherence."1

\section{Introduction}

In 1993 the General Medical Council (GMC) published Tomorrow's Doctors. ${ }^{2}$ Central to this blueprint for medical education was the recognition that being a good doctor is about more than possessing adequate knowledge and skills. The importance of the acquisition and demonstration of appropriate attitudes was highlighted by the GMC and this reflected a growing impatience on the part of the public with doctors who communicated poorly and appeared to pay little attention to the patient's views and opinions. The care of patients with cancer is an area where appropriate attitudes and empathy can transform adequate care into good care.

Fortunately, most doctors, qualifying in their mid-twenties, have little personal experience of cancer. Unfortunately, in the context of traditional undergraduate teaching, students may have little opportunity to reflect on the impact cancer has on patients and families and, importantly, on the professionals who care for them. Yet they will be asked, all too soon, to address the psychological and emotional needs of cancer patients and their families and may at the same time experience anxiety and distress from their own role as professional carers. This potential gap, between the expectations of doctors' performances and the ability of traditional training to prepare them to meet these expectations, motivated us to develop this course. We were encouraged by the experience of others, where specific efforts to provide students with a fuller appreciation of the impact of cancer have resulted in impressive improvements in student attitudes, knowledge and self-directed learning. ${ }^{3}$ The introduction of special study modules following the GMC's recommendations provided the opportunity to do this. ${ }^{45}$

\section{Design and delivery}

Throughout the design and delivery of this course we aimed to bridge this experiential gap. Working with expert tutors in fine art, art therapy and drama and clinicians with additional expertise in ethics, medical anthropology and medical history, the arts were used to enable the students to enter the "cancer world" of patients, families and professionals.

The following were identified as desirable aims for the course. First it was felt that students should appreciate the wider role of the arts in health care and the variety of different art media that can be used to tell the stories of illness and communicate emotions and attitudes. ${ }^{6-8}$ Second, having identified this resource with the students we then aimed to equip them with the necessary analytical and interpretive skills to use the arts for their professional and personal development. ${ }^{9}{ }^{10}$

This would be achieved through skilled facilitation of in-depth analysis of literature, film and art. A strong emphasis was placed on re-kindling and developing the students' own creative outlets 


Box one: Seminars
- an introductory seminar to ground the students in the
unfamiliar territory of a creative course, to
acknowledge the sensitive issues involved and to
outline support mechanisms available.
- a seminar, co-tutored with the widow of a writer,
where the motivation and consequences of writing
about one's own illness are explored.
- three seminars where critical analysis of poetry and
prose provide insight into the impact of cancer on the
patients, carers and professionals.
- a seminar examining the portrayal of cancer in a
contemporary film and the strengths and weaknesses of
this media in this context.
- two seminars, involving hands-on work with paints,
allowing students to discover the potential of art to
express the emotions cancer evokes and the benefits
this can have both for the artist and for those who view
the work.
- three drama seminars providing a creative outlet for
the students' experiences throughout the course and
culminating in an original production of the students'
making.

through hands-on use of art materials and by an exercise in creative writing. In addition we decided to provide an outlet for their powers of expression by allowing them to use drama to portray what cancer can mean to all those who are affected by it. With these objectives in mind we identified a body of work, including poetry, prose, biographical and journalistic accounts of cancer, film and fine art, as appropriate teaching materials. ${ }^{11}$ This material was then assessed for its ability to help achieve the aims of the course and of specific seminars. In addition specialist tutors were identified who have been integral in the ongoing evaluation and development of the course.

\section{Content}

Twenty-two students have taken part in this course to date. We have provided a synopsis of the seminars for students (box one) as well as our thoughts on those aspects of the course design that proved key to successful delivery (box two). For a detailed description of how to deliver a similar course the reader is referred to the educational pack produced by DK for the Cancer Research Campaign. ${ }^{12}$ A list of the required reading for the course is provided at the end of this paper and we hope this will be of use to others developing similar courses.

\section{Student assessment}

Students were assessed on the basis of their attendance and participation, their written work, the dramatic presentation and using four Objective Structured Clinical Examination (OSCE) stations. The OSCE stations tested attitudes to truth-telling and breaking bad news, respect for patient views and beliefs, team work, confidentiality and respect for dignity as well as exploring the students' understanding of some of the psychosocial problems associated with living with cancer. The development of these OSCE stations are described in detail elsewhere. ${ }^{13}$

\section{Student evaluation of the course}

Students filled out basic evaluation forms after each seminar and completed an end-of-course evaluation for the medical school registry. A more personalised and qualitative face to face evaluation was conducted with each individual student by DK and RM. Overall the course was rated second highest by students of all SSMs provided within the medical school. Particularly revealing, however, were individual comments by students. One student said that it was the first time in her training when what she thought, as opposed to what she knew, was acknowledged as important. Another commented that:

"It took me off the 'treadmill' of clinical attachments and provided me with an invaluable understanding of human needs including my own."

A third said that it made him feel like a "real student". On further questioning he said he meant that a proper student has to think whereas medical students have merely to regurgitate. An additional perspective came from students who were assigned to the course by the medical school registry, because their first choice SSM was not available. Five of the twenty-two students who have taken part in the course over the last two years were assigned in this way. We were initially anxious about this possibility but our experience has challenged our immediate concern that assigning students to such an emotive and creative course should be discouraged. One student, who was assigned to the course, revealed to us on the last day that a close family experience of cancer had made the course unattractive when choosing SSMs. At the end of the course that student had been able to discuss his feelings about that cancer, with his family, for the first time since the diagnosis several years previously. The student summed up his feelings about the course by saying:

"It is the people who don't want to do the course who need it most."

All of the assigned students confirmed that the course had been extremely valuable to them and all indicated that given the opportunity they would opt for a humanities course in the future. 


Box two: Keys to success
- a dedicated course co-ordinator with a close working
knowledge of the students.
- an enthusiastic and proactive team of tutors with clearly
understood aims and objectives.
- a system of student support, including mechanisms for
identifying students who need extra support.
- continuous audit and feedback throughout the course so
that teaching can be customised as the dynamics of the
group evolves.
- a pleasant and relaxing teaching environment with
appropriate provision for breaks to allow students to provide
each other with support and tutors to reflect on how the
session is progressing.
- a plenary session when students and tutors can reflect,
provide feedback on and evaluate their experiences of the
course and make suggestions for the future.
- An individual feedback to students when their overall
contribution and creative writing in particular can be
discussed and when personal insights and experiences can
be shared sometimes for the first time.

\section{Experience to date}

Student and tutor enthusiasm for this course has been high and two further humanities SSMs have been developed and delivered in our unit as a result of this enthusiasm. Since this was a new course we were particularly keen to incorporate student and tutor feedback into the ongoing development of the course. The greatest student complaint at the end of the first two courses was that there was inadequate time for the drama and for the fine art. The time allotted for drama was subsequently changed from two to three seminars. This sentiment was particularly noteworthy during one course, where three students had made no fewer than three delegations to us seeking an exemption from this part of the course. This was partly due to religious reasons for one student and also because of the anxiety generated by the prospect of acting. All three delegates subsequently rated the drama as the best aspect of the course. The other main suggestion for change was to have less literature. Although the value of the literature was undisputed by the students they felt emotionally exhausted by the content of the readings. They did, however, appreciate that it is the very intensity of the written material about this particular subject matter that makes the learning so productive. In response to this feedback we have reduced the literature-based sessions from four to three and increased the fine art from one to two sessions.

All of the main student suggestions for improvement were thus incorporated into the third course and the balance of different teaching modalities was well received by the students. In addition the greater space allowed for the students' own creativity had the unanticipated benefit of allowing their interpretive and analytical skills to develop more rapidly. By the time they reached the last session, using literature to explore the professional's perspective, they were essentially ready to lead the seminar themselves. This was a cause of much satisfaction to the organisers although initially it startled the session leader.

\section{Integration into the wider curriculum}

One of us (DK), who is a clinical lecturer in communications skills, has incorporated medical humanities teaching methods into communications teaching as a direct result of her experience coordinating this course. The fine art workshop has been modified to explore the students' own feelings about cancer and to acknowledge the impact this can have when professionals have to break bad news to patients. In addition poetry and prose have been incorporated into communications teaching and this has been well received by students. Moreover the success of the humanities SSMs provided by our unit have encouraged others within the department to view humanitiesbased teaching as a viable approach and has stimulated a growing interest in colleagues who previously had given little thought to this area.

\section{Conclusion}

Humanities special study modules of the kind described allow space and time for medical students to stand back and reflect on the enormity of the task they are expected to undertake. Equally importantly it equips them to access the wealth of human experience that is embodied in the arts. This vicarious experience can then both inform and direct them in their search for the wisdom and the humanity to fulfil their role as clinicians. The insight demonstrated in our students' creative writing should, we believe, be heartening to the patients they will care for. The reader is referred to the anthology of student works that is to be published by the Cancer Research Campaign. ${ }^{14}$ We would highly recommend humanities-based teaching to both students and tutors. As exciting developments take place in medical humanities in the UK ${ }^{15}{ }^{16}$ we look forward to hearing from the many groups around the coutry who are making a more humanistic approach to medical education a reality for tomorrow's doctors.

\section{Required reading}

"On the Sick". Extracts from Odd Man Out by Martyn Harris, London, Pavilion Books Ltd 1996.

"Teach me to hear mermaids singing" by Clare Vaughan, British Medical fournal 1996:313:565. 
"C ... because cowards get cancer too" by John Diamond (extracts), London, Vermillion, 1998.

Poems from The Patient Knows, by A Savage and J Brighton, Tredegar, Gwent, Marches Cancer Care, 1997.

"First you cry" by Betty Rollin in Ordinary Lives: Voices of Disability and Disease, by Irving Zola, Cambridge, Applewood books, 1982.

Before I Say Goodbye. Extracts from the book of that name by Ruth Picardie and Matt Seaton, Harmondsworth, Penguin Books 1998.

"The infinite dark" by Mary Alice Ayers, from Life on the Line: Selections on Words and Healing edited by Sue Walker and Rasaly Roffman, Mobile, Alabama, Negative Capability Press, 1992.

"Flight" by James Loader from Cold Comfort edited by James Loader, London, Serpent's Tail 1996.

"One last time" by Lori Russell from If I had My Life Over I Would Pick More Daisies edited by Sandra Martz, Watsonville, Carolina: Papier Mache Press, 1992.

"Last things" by Debra Spark from Ploughshares, Boston, Massachusetts, 1994.

"Mercy" from Letters to a Young Doctor by Richard Selzer, San Diego, Harvest Books, Harcourt Brace, 1982.

"Around every tumour there's a person" by Surinder Singh, British Medical fournal 1998; 316:319-20.

"The fat lady" by Eliza Fewett from Cold Comfort edited by James Loader, London, Serpent's Tail, 1996.

"The dissecting room" by C Helman. In: The Body of Frankenstein's Monster: Essays in Myth and Medicine, New York: WN Norton, 1992.

\section{Acknowledgements}

We would like to thank the Cancer Research Campaign for the initial funding and support in the development and delivery of this project.

Deborah Kirklin is Lecturer in Medical Humanities and Clinical Lecturer in Communication Skills, the Medical Humanities Unit, Department of Primary
Care and Population Sciences, Royal Free and University College Medical School, London. Richard Meakin is Senior Lecturer and Director of the Medical Humanities Unit; Surinder Singh is Lecturer in Primary Care, the Medical Humanities Unit, and Margaret Lloyd is Reader in Primary Care, the Medical Humanities Unit. Address for correspondence: Dr Deborah Kirklin, Lecturer in Medical Humanities, The Medical Humanities Unit, Department of Primary Care and Population Sciences, Royal Free Campus, Rowland Hill Street, London NW3 2PF.email:d.kirklin@rfhsm.ac.uk

\section{References}

1 Harris M. Odd man out. London: Pavilion Books Ltd, 1996: 302.

2 General Medical Council. Tomorrow's doctors - recommendations on undergraduate medical education. London: General Medical Council, 1993.

3 Finlay IG, Maughan TS, Webster DJ. A randomised controlled study of portfolio learning in undergraduate cancer education. Medical Education 1998;32,2:172-6.

4 Downie RS, Hendry RA, Macnaughton RJ, Smith B. Humanising medicine: a special study module. Medical Education, 1997;31,4:276-80.

5 Macnaughton RJ. Special study modules: an opportunity not to be missed. Medical Education 1997;31,1:49-51.

6 Laderman C, Roseman M, eds. The performance of healing. New York and London: Routledge, 1996.

7 Haldane D, Loppert S, eds. The arts in health care: learning from experience. London: King's Fund Publishing, 1999.

8 Downie RS, ed. The healing arts: an Oxford illustrated anthology. Oxford: Oxford University Press, 1994.

9 Brody H. Stories of sickness. New Haven: Yale University Press, Brody 1997.

10 Hudson Jones A. Literature and medicine: narrative ethics. Lancet 1997;349:1243-6.

11 Meakin R, Kirklin D, Singh S, Lloyd M. Living with and dying from cancer: developing a humanities-based special study module for undergraduate medical students. London: Royal Free \& University College Medical School, 2000.

12 KirklinD, Meakin R, Singh S, Lloyd M. An educational pack for the humanities-based special study module: living with and dying from cancer. London: Royal Free \& University College Medical School, 2000.

13 Kirklin D, Singh S, Meakin R, Lloyd M. Attitudinal objective structured clinical examinations: their value as an assessment tool in cancer. London: Royal Free \& University College Medical cancer. London: 2000.

14 Meakin R, Kirklin D, eds. I thought I had a lifetime. London: Royal Free \& University College Medical School, 1998.

15 Evans M, Greaves D. Exploring the medical humanities [editorial]. British Medical fournal 1999;319:1216.

16 Knight S. Council aims to integrate arts and humanities into the NHS. British Medical fournal 1999;319:1222. 